\title{
Uterine rupture in a teaching hospital in Mbarara, western Uganda, unmatched case- control study
}

Peter K Mukasa ${ }^{1,2^{*}}$, Jerome Kabakyenga ${ }^{3}$, Jude K Senkungu ${ }^{3}$, Joseph Ngonzi $^{3}$, Monica Kyalimpa ${ }^{4}$ and Van J Roosmalen ${ }^{5,6}$

\begin{abstract}
Background: Uterine rupture is one of the most devastating complications of labour that exposes the mother and foetus to grave danger hence contributing to the high maternal and perinatal mortality and morbidity in Uganda. Every year, 6000 women die due to complications of pregnancy and childbirth, uterine rupture accounts for about $8 \%$ of all maternal deaths.

The objective of this study was to establish the incidence of uterine rupture, predisposing factors, maternal and fetal outcomes and modes of management at a regional referral university hospital in South-western Uganda.
\end{abstract}

Methods: Case-control design of women with uterine rupture during 2005-2006. Controls were women who had spontaneous vaginal delivery or were delivered by caesarean section without uterine rupture as a complication. For every case, three consecutive in-patient chart numbers were picked and retrieved as controls. All available case files, labour ward and theater records were reviewed.

Results: A total of 83 cases of uterine rupture out of 10940 deliveries were recorded giving an incidence of uterine rupture of 1 in 131 deliveries. Predisposing factors for uterine rupture were previous cesarean section delivery(OR $5.395 \% \mathrm{Cl}$ 2.7-10.2), attending < 4 antenatal visits (OR $3.395 \% \mathrm{Cl} 1.6-6.9$ ), parity $\geq 5(\mathrm{OR} 3.67$ 95\% Cl 2.0-6.72), no formal education (OR $2.095 \% \mathrm{Cl}$ 1.0-3.9), use of herbs (OR15.2 95\% Cl 6.2-37.0), self referral (OR 6.1 95\% Cl 3.3-11.2) and living in a distance $>5 \mathrm{~km}$ from the facility (OR $10.8695 \% \mathrm{Cl}$ 1.46-81.03). There were 106 maternal deaths during the study period giving a facility maternal mortality ratio of $1034 / 100,000$ live births, there were 10 maternal deaths due to uterine rupture giving a case fatality rate of $12 \%$.

Conclusion: Uterine rupture still remains one of the major causes of maternal and newborn morbidity and mortality in Mbarara Regional referral Hospital in Western Uganda. Promotion of skilled attendance at birth, use of family planning among those at high risk, avoiding use of herbs during pregnancy and labour, correct use of partograph and preventing un necesarry c-sections are essential in reducing the occurences of uterine repture.

Keywords: Uterine rupture, Maternal morbidity, Obstructed labour, Fetal outcome, Obstetric fistula, (previous) Caesarean section, Prolonged labour

\section{Background}

Worldwide, every year, between 340,000 and half a million women die due to complications of pregnancy and child birth, the majority of these occurring in low income countries. Sub- Sahara Africa bears over 90 percent of the burden [1-3].

\footnotetext{
* Correspondence: mukasapk@yahoo.com

${ }^{1}$ Ministry of Health, 7272, Kampala, Uganda

2UNFPA, Uganda Country office, P.O. BOX 7184, Kampala, Uganda

Full list of author information is available at the end of the article
}

Uterine rupture, one of the major obstetric complications of labour contributes significantly to maternal and perinatal mortality and morbidity [4-8]. The occurrence of uterine rupture varies in different parts of the world. While it is rare in high-income countries, it remains a public health problem in low income countries, particularly in Africa and mainly occurring as consequence of prolonged, obstructed labour [6-8].

Uganda like any other country in Sub-Sahara Africa still struggles with poor reproductive health indicators. Every year, 6000 women die due to complications of

\section{Biomed Central}

(c) 2013 Mukasa et al.; licensee BioMed Central Ltd. This is an Open Access article distributed under the terms of the Creative Commons Attribution License (http://creativecommons.org/licenses/by/2.0), which permits unrestricted use, distribution, and reproduction in any medium, provided the original work is properly cited. 
pregnancy and childbirth, uterine rupture accounts for about $8 \%$ of all maternal deaths [5,9-13]. A high incidence of uterine rupture is an indicator of poor obstetric care, poor accessibility to the few available comprehensive Emergence Obstetric Care (EmoC) facilities as well as a poor socio-economic condition of the community [14-18].

In high income countries, the majority of cases occur in women with previous caesarean section, while in low income countries, it usually results from prolonged obstructed labour, often in unscarred uterus. However, most cases are usually associated with a combination of risk factors including grand multiparty, advanced age, fetal macrosomia and abnormal placentation $[6-8,19,20]$.

This study aimed at establishing the incidence of uterine rupture, predisposing factors, maternal and fetal outcomes and modes of management at a regional referral university hospital in South-western Uganda.

\section{Materials and methods Study setting}

The study setting was Mbarara University of Science and Technology teaching hospital which is located in Mbarara Municipality, and $286 \mathrm{~km}$ south west of Kampala the Capital city of Uganda. It is a public hospital funded by Government of Uganda through the Ministry of Health. It is the referral hospital for south western Uganda serving 10 districts with a population of more than 2.5 million people. It also receives patients from neighbouring countries of Rwanda, Tanzania and Democratic Republic of Congo. It handles on average 10,000 deliveries per year.

\section{Case definition and selection}

Uterine rupture was defined as tearing of the uterine wall either partially or complete during pregnancy and labour, diagnosed either clinically and later confirmed at laparotomy. The cases were retrospectively collected from the maternity ward and operating theatre registers as well as from the patients' case files at the hospital medical records office.

\section{Selection of controls}

Controls were women who had spontaneous vaginal delivery or were delivered by caesarean section without uterine rupture as a complication. For every case, three consecutive in-patient chart numbers were picked and retrieved as controls.

\section{Data collection}

Data was abstracted from the maternity ward and operating theatre registers as well as from the patients' case files at the hospital medical records office using a pre tested case report form (CRF). Information on the patients' age, tribe, address, occupation, religion, parity, previous caesarean section, antenatal care attendance, estimated distance of residence from the hospital, place of intrapartum care, subsequent rupture, type of surgical intervention (total or sub-total hysterectomy, repair without bilateral tubal ligation [BTL] or repair with BTL), maternal and foetal outcomes, length of postoperative hospital stay and other relevant information were collected. The total number of cases of uterine rupture and deliveries from the maternity ward admission register was validated with the annual Health Management Information System (HMIS) reports.

The data collectors were midwives who were trained to collect data from women's obstetric files or charts and to validate the diagnosis of obstructed labour using admission, delivery and theatre registers. Thought the data collection period which lasted 4 weeks, I was providing oversight and supervision to prevent under reporting.

\section{Statistical analysis}

The data were entered and analyzed using SPSS statistical software, version 12.0 (SPSS, Chicago, IL, USA). Descriptive statistics were obtained through frequencies and cross tabulations. Comparison between groups was made using the $\mathrm{x}^{2}$ tests and Fisher exact test when appropriate. All analyses were two-tailed and the level of significance was set at $5 \%$.

\section{Ethical considerations}

Ethical approval was obtained from Mbarara University Institutional Ethical Research Committee. Permission to access obstetric records was obtained from the medical director of the hospital and these were anonymously entered into the database.

\section{Results}

Between January 2005 and December 2006, there were 10,940 deliveries, 10246 live births, 694 still births, giving a stillbirth rate of 68 per 1000 live births and 106 maternal deaths, giving a facility ratio of 1035 per 100,000 live births.

Eight three cases of uterine ruptures were managed during the study period, giving an overall incidence rate of $0.76 \%$ or 1 in 131 deliveries. There were 10 maternal deaths due to uterine rupture giving a case fatality rate of $12 \%$. Fresh stillbirths occurred in $80.5 \%$ of the cases. Only 77 out of 83 charts were recovered from the registry and hence analyzed for this study. We had to exclude 44 (17\%) of the control charts for lack of insufficient information.

$75.3 \%$ of the cases were in the $20-34$ age range which is similar to $75.5 \%$ in the $20-34$ age range of the controls. The lowest incidence of uterine rupture was among the less than 19 year old age group. 
The majority of the women $74 \%$ versus $82 \%$ attended antenatal care, and mostly getting care from health centres. Those who used herbs were $35.1 \%$ among the cases as compared to only $3.4 \%$ among the controls [Table 1].

Predisposing factors for uterine rupture were previous caesarean section (OR 5.3; 95\% CI 2.7-10.2), attending $<4$ antenatal visits (OR 3.3; 95\% CI 1.6-6.9), parity $\geq 5$ (OR 3.67; 95\% CI 2.0-6.72), no formal education (OR 2.0; 95\% CI 1.0-3.9), use of herbs (OR 15.2; 95\% CI 6.237.0), self referral (OR 6.1; 95\% CI 3.3-11.2) and living in a distance $>5 \mathrm{~km}$ from the facility (OR 10.86; 95\% CI 1.46-81.03), lack of partograph use (OR 19.57; 95\% CI 2.65-144.8) and referral from facility(OR 6.14; 95\% CI 3. 37-11.2) [Table 2].

Total abdominal hysterectomy was done in 22 (28.6\%) women with uterine rupture, subtotal hysterectomy in $29(37.7 \%)$, uterine repair with BTL in 4 (5.2\%) and uterine repair without BTL in 22 (28.6\%) [Table 3].

\section{Discussion}

The incidence of uterine rupture in this study was 1in 131 deliveries $(0.76 \%)$, which is slightly higher than other recent studies done in Uganda in which the incidence was 1 in 200 deliveries. This shows that uterine rupture contributes greatly to the maternal and new born morbidity and mortality in western Uganda and is a reflection of the flaws in the health system in the region

Table 1 Demographic characteristics of study participants

\begin{tabular}{lll}
\hline Characteristics & $\begin{array}{l}\text { Cases } \\
\mathbf{n = 7 7} \\
\mathbf{( \% )}\end{array}$ & $\begin{array}{l}\text { Controls } \\
\mathbf{n = 2 0 5} \\
\mathbf{( \% )}\end{array}$ \\
\hline Age group & & \\
$\leq 19$ years & $5(6.5)$ & $32(15.6)$ \\
20-34 years & $58(75.3)$ & $153(72.5)$ \\
$\geq 35$ years & $14(18.2)$ & $20(9.8)$ \\
Married & $72(93.5)$ & $194(94.6)$ \\
Secondary education and above & $15(19.5)$ & $68(33.2)$ \\
Para 5 and above & $29(37.7)$ & $29(14.1)$ \\
Living within a distance of 5 km from health & $1(1.3)$ & $26(12.9)$ \\
facility & & \\
ANC attendance & $57(74)$ & $168(82)$ \\
Place of antenatal & & \\
Hospital & $13(22.9)$ & $69(41.1)$ \\
Health centre & $42(73.7)$ & $87(51.8)$ \\
TBA & $1(1.8)$ & $3(1.8)$ \\
Referred from facility & $38(36.4)$ & $28(14.0)$ \\
Partograph used during labour & $1(1.3)$ & $42(20.5)$ \\
Previous caesarean section & $28(36.4)$ & $20(9.8)$ \\
Use of herbs in during labour & $27(35.1)$ & $7(3.4)$ \\
\hline ANC Antenat care $7 B A$ Traditionat birth attendant. & & \\
\hline
\end{tabular}

ANC Antenatal care, TBA Traditional birth attendant.
Table 2 Associated risk factors for uterine ruptures among study participants

\begin{tabular}{lllll}
\hline Variable & Cases & Controls & Odds ratio $(\mathrm{Cl})$ & p-valu \\
& $\mathbf{n = ( \% )}$ & $\mathbf{n = ( \% )}$ & & \\
\hline \multicolumn{2}{l}{ Previous caesarean section } \\
Yes & 28(36) & 20(10) & $5.3(2.7-10.2)$ & 0.00 \\
No & $49(64)$ & $185(90.2)$ & &
\end{tabular}

Attended antenatal care(ANC)

\begin{tabular}{|c|c|c|c|}
\hline & $57(74)$ & $168(82)$ & $0.62(0.33-1.2)$ \\
\hline
\end{tabular}

Number of visits attended for antenatal care

\begin{tabular}{|c|c|c|c|c|}
\hline$<4$ times & $47(82.5)$ & $99(58.9)$ & $3.3(1.6-6.9)$ & 0.002 \\
\hline$\geq 4$ times & $10(17.5)$ & 6941.1) & & \\
\hline \multicolumn{5}{|l|}{ Parity } \\
\hline$\geq 5$ & 29(38) & $29(14)$ & $3.67(2.0-6.72)$ & 0.000 \\
\hline$\leq 4$ & $48(62)$ & $176(86)$ & & \\
\hline \multicolumn{5}{|l|}{ Education level } \\
\hline None or primary & $62(81)$ & $137(67)$ & $2.05(1.09-3.87)$ & 0.026 \\
\hline Secondary and above & 15(19) & $68(33)$ & & \\
\hline
\end{tabular}

\section{Partograph use}

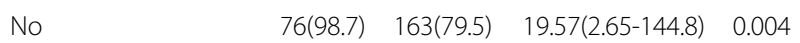

yes $\quad 1(1.3) \quad 42(20.5)$

Use of herbs

$\begin{array}{lllll}\text { Yes } & 27(35) & 7(3) & 15.27(6.2-37.09) & 0.000\end{array}$

no 50(65) 198(97)

Referred

$\begin{array}{lllll}\text { From facility } \quad 38(49) & 33(16) & 6.14(3.37-11.2) & 0.000\end{array}$

self 39(51) 172(84)

Distance travelled from home to facility

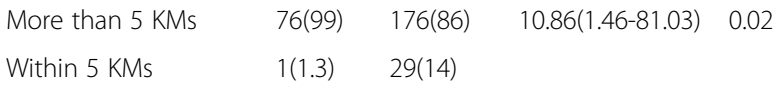

$[5,10,21,22]$. Other studies in sub-Saharan Africa have also reported almost similar results as compared to 1 in $1536(0.07 \%)$ in high income countries where there is a wider availability and utilisation of medical services is [6-8,19,23-26].

For this study period, there were 106 maternal deaths in the hospital and 10 of these where due to uterine rupture giving a facility maternal mortality ratio of 1034 per 100,000 live births and a case facility rate of $12 \%$, which is well above the less than $1 \%$ fatality rate recommended by World Health Organisation [27]. This could be compared with other studies done from developing countries and explained by the enormous challenges of access for quality services highlighted in the 3 delays model by Maine, including delays of reaching facilities, our facility being a regional referral, women often come in critical condition resulting in poor 
Table 3 Types of operations done

\begin{tabular}{ll}
\hline Operation procedure & N (\%) \\
\hline Total abdominal hysterectomy & $22(28.6)$ \\
Total abdominal hysterectomy & $29(37.7)$ \\
Repair of the uterus & $22(28.6)$ \\
Repair of the uterus and bilateral tubal ligation & $4(5.2)$ \\
\hline
\end{tabular}

outcomes and in developed countries, the case fatality ranges between $0-1 \%[27,28]$.

Only $19.5 \%$ live births were recorded among the mothers with uterine rupture, the majority $(16.2 \%)$ were from scar uterine rupture, which is in the range reported in some countries [15,19,29-37]. To avoid these high mortalities, there is need to put in place systems for timely diagnosis, stabilization and interventions [25]. All these finding show important operational deficiencies in the provision of obstetric care in Uganda [26].

Despite high use of antenatal care, over $94 \%$ for first visit in Uganda, deliveries at health facilities has remained low $42 \%$, Emergency Obstetric Care met need is only $14 \%$. Postnatal care (PNC) coverage is very low and maternal mortality, perinatal and neonatal mortality have remained high at 435 per 100,000 live births, 36 per 1,000 live births, 29 per 1000 live births respectively $[11,38,39]$.

In this current study, over $82 \%$ of the cases attended antenatal care less than the recommended 4 times and were 3 times more likely to sustain uterine rupture and these are likely to deliver at home with no birth preparedness compared to those who attended 4 times, such results have been reported in other studies in Ethiopia and Nigeria $[17,34,35]$.

Majority of the cases (64\%) and controls (90.2\%) in this study had no history of previous caesarean section or operation on the uterus which is in agreement with a study from Nigeria and other sub Saharan countries as most of the uterine ruptures are associated with obstructed labour. Those who had a history of previous caesarean section were 5 times more likely to sustain uterine rupture and this in agreement with other studies especially in high income countries, this could be explained that there could have been some degree of post partum infection and hence weaken the scar $[7,20,36,37]$.

Many have considered multiparity as a risk factor for uterine rupture, in this study, those with parity $\geq 5$ were four times likely to get uterine rupture. This could be explained that in women with less parity and especially in primigravidas, when mechanical obstruction occurs, uterine contractions gradually become weaker and stop, while in multi-parious women, the contractions often continue till delivery and end up with uterine rupture [17,21].

Most studies have indicated that lower socio economic status in combination with lack of education are associated with poor health seeking behaviour and access to care, hence resulting into high proportions of lack of skilled attendance at birth, prolonged labour and uterine rupture [34-38]. In this study, women with no education or those who ended in primary education were two times more likely to sustain uterine rupture and this in agreement with other studies that found that women with no formal education were more prone to no use of antenatal care, skilled birth attendance, postnatal care and use of family planning methods [39-46].

Appropriate use of the partograph is an important tool for audit and monitoring progress of labour and a warning device to detect deviations from normal labour, preventing obstructed labour and thereby improving maternal and fetal outcome [47-49]. However, its use has been a challenge in most facilities probably due to lack of skills, negative attitudes by service providers and lack of papers. Not using a partograph was 19 times more likely to result in uterine rupture. All these factors have to be considered in planning for implementation of proper use of partographs in health settings [47].

Use of herbs as complementary medicines during pregnancy and labour is common in our setting and is compounded by many cultural and traditional briefs $[49,50]$. These herbs are thought to have oxytoxic ingredients and those who take them during labour tend to get hyper stimulation of the uterus leading to uterine rupture and fetal hypoxia and demise. In this study, those who used herbs during labour were 15 times more likely to get uterine rupture than who did not.

Ministry of Health recommends that for easy access to emergency obstetric care, the community is served by a health facility which is in a distance of less than $5 \mathrm{kms}$. In this study, all the mothers came from a distance far more than $5 \mathrm{kms}$ and they were 10 times more likely to get uterine rupture due long distances, delays to reach and poor road network [11-13].

Proper diagnosis is paramount and this is based on clinical signs and symptoms of uterine rupture. Proper stabilization of the patient before surgery is critical as this improves outcome and prognosis. Modes of management of uterine rupture will be based on the extent of rupture, desire of mother, the number of children she has, the decision and experience of the physician on the operating table in theatre. Modes of management include total hysterectomy, subtotal hysterectomy $[8,15,19,29-35]$, repair with bilateral and repair without tubal ligation. However, there is need to get informed consent for sterilization from the patient or couple [51,52].

\section{Study limitations}

This being a facility based study; the findings may not be generalised to the general population. Due to the retrospective nature of the study, much information was missing in the charts and maternity registers and hence 
a great possibility of underreporting. May be the small sample size of the study may have limited our ability to detect small differences.

\section{Implications for practice}

There is a need to address third delay at the health facilities since facility level preparedness to respond to obstetric and newborn emergencies is critical for the survival of women and their newborns. Health facilities especially at primary level need to be supported with adequate skilled birth attendants, equipment, drugs and supplies for appropriate care during pregnancy and child birth. Government of Uganda needs to implement the Road Map which has been developed to reach the rural woman and sensitise them on birth preparedness, skilled attendance, and safe motherhood and empower them with knowledge to seek health care. Since over $90 \%$ of women attend antenatal care at least once during pregnancy, there is a need to utilize this opportunity to counsel women and their husbands if available on birth preparedness In addition, partographs should be available in all facilities and used correctly.

\section{Conclusions}

Uterine rupture still remains one of the major causes of maternal and newborn morbidity and mortality in Mbarara Regional referral Hospital in Western Uganda. Promotion of skilled attendance at birth, use of family planning among those at high risk, avoiding use herbs during pregnancy and labour, correct use of partograph and preventing un necesarry c-sections are essential in reducing the occurences of uterine repture.

\section{Competing interests}

The authors declare that they have no competing interests.

\section{Authors' contributions}

PKM, JK, MK, VRM conceived and designed the study, developed data collection instruments and supervised data collection. PKM, JS, JN, MK participated in the testing and finalization of the data collection instruments and coordinated study progress JS, PKM, JK performed the statistical analysis, PKM wrote all versions of the manuscript.VRM gave in put during statistical analysis mentored PKM on writing all the versions and critically reviewed all the versions. All authors read and approved the final manuscript.

\section{Acknowledgements}

We would like to acknowledge the efforts of midwives who collected the data, the hospital staff and administration for their valuable time and effort rendered during the course of this study. Special go to Dr Wasswa Ssalongo for the clinical guidance and mentorship.

\section{Author details}

${ }^{1}$ Ministry of Health, 7272, Kampala, Uganda. ${ }^{2}$ UNFPA, Uganda Country office, P.O. BOX 7184, Kampala, Uganda. ${ }^{3}$ Mbarara University of Science and Technology, Faculty of Medicine, P.O. BOX 1410, Mbarara, Uganda. ${ }^{4}$ School of Nursing Sciences, Kampala International University, Western Campus, P.O. BOX, 71, Ishaka-Bushenyi, Uganda. ${ }^{5}$ Department of Obstetrics, Leiden University Medical Centre, Leiden, Amsterdam, the Netherlands. ${ }^{6}$ Department of Medical Humanities, EMGO Institute of Health and Care Research, VU University Medical Centre, Amsterdam, the Netherlands.
Received: 19 July 2012 Accepted: 26 May 2013

Published: 29 May 2013

\section{References}

1. Hogan MC, Foreman KJ, et al: Maternal mortality for 181 countries, 1980-2008: a systematic analysis of progress towards millennium development goal 5". Lancet 2010, 375(9726):1609-1623.

2. World Health Organization: Trends in maternal mortality 1990 to 2008, Estimates developed by WHO, UNICEF, UNFPA and the world bank. Geneva: WHO Press; 2010.

3. Khan KSW: WHO analysis of causes of maternal death: a systematic review. Lancet 2006, 367:1066-1074.

4. Kaye, DK, Kakaire O, Osinde MO: Sytematic review of the magnitude and case fatality ratio for severe Maternal morbidity in sub-Saharan Africa between 1995 and 2010. BMC Pregnancy Childbirth 2011, 11:65. Review.

5. World Health Organization: Report on the World Health Organization working group on the classification of maternal deaths and severe maternal morbidities. Geneva: World Health Organization; 2009.

6. Souza JP, Cecatti JG, Parpinelli MA, de Sousa MH, Serruya SJ: Systematic review of near miss maternal morbidity. Cad Saude Publica 2006, 22:255-264.

7. Ronsmans C, Filippi V: Beyond the numbers reviewing maternal deaths and complications to make pregnancy safer: reviewing severe maternal morbidity: learning from women who survive life threatening complications. Geneva: World Health Organization; 2004.

8. van den Akker T, Beatrice M, James I, van Roosmalen J: Using audits to reduce the incidence of uterine rupture in a Malawian district hospital. Int J obstetric Genecol 2009, 107(3):289-294.

9. Koblinsky MA: Beyond maternal mortality-magnitude, interrelationship, and consequences of women's health, pregnancy related complications and nutritional status on pregnancy outcomes. Int J Gynecol Obstet 1995, 48:S21-S32.

10. Ponndara I, Dawson A, Homer CSE, Whelan AK: Practices of skilled birth attendants during labour, birth and the immediate postpartum period in Cambodia. Midwifery 2013, 29(4):300-3007.

11. UBOS, Macro International Inc: Uganda Demographic and Health Survey 2006. Calverton, Maryland, USA: UBOS and Macro International Inc; 2007. http://www.measuredhs.com/pubs.

12. Ministry of Health $(\mathrm{MOH})$ : Roadmap for accelerating the reduction of maternal and neonatal mortality and morbidity in Uganda 2007-2015. Kampala, Uganda: Ministry of Health Press; 2007.

13. Ministry of Health, U: Health sector strategic plan II 2005/06 - 2009/10. Kampala, Uganda: Ministry of Health Press; 2007.

14. Hofmeyr GJ, Say L, Gulmezoglu AM: WHO systematic review of maternal mortality and morbidity: the prevalence of uterine rupture. BJOG 2005, 112:1221-1228.

15. Zwart J, Richters J, O” ry F, de Vries J, Bloemenkamp K, van Roosmalen J: Uterine rupture in the Netherlands: a nationwide population-based cohort study. BJOG 2009, 116:1069-1080.

16. Ezechi OC, Mabayoje P, Obiesie LO: Ruptured uterus in South Western Nigeria. A re-appraisal. Singapore Med J 2004, 45:113-116.

17. Gassessew A, Melese M: Ruptured uterus - eight year retrospective analysis of causes and management outcome in Adigrat Hospital, Tigray region, Ethiopia. Ethiopia J Health Dev 2002, 16:241-245.

18. Chen LH, Tan KH, Yeo GS: A ten year review of uterine ruptures in modern obstetric practice. Ann Acad Med Singapore 1995, 24:830-835.

19. Kwee A, Bots ML, Visser GH, Bruinse HW: Obstetric management and outcome of pregnancy in women with a history of caesarean section in the Netherlands. Eur J Obstet Gynecol Reprod Biol 2007, 132:171-176.

20. Kaczmarczyk M, Sparen $P$, Terry P, Cnattingius S: Risk factors for uterine rupture and neonatal consequences of uterine rupture: a populationbased study of successive pregnancies in Sweden. BJOG 2007, 114(10):1208-1214.

21. Konje JC, Odukoya OA, Ladipo OA: Rupture uterus in Ibadan. A twelve year review. Int J Gynaecol Obstet 1990, 32:207-213.

22. Ebeigbe $P N$, Enabudoso $E$, Ande $A B$ : Rupture uterus in a Nigeria community: a study of socio demographic and obstetric risk factors. Acta Obstet Gynaecol Scand 2005, 84:1172-1174.

23. Ezegwui HU, Nwogu-lkojo EE: Trends of uterine rupture in Enugu, Nigeria. J Obstet Gynaecol 2005, 25:260-262. 
24. Nahum GG: Krystle Quynh Pham 2010, Uterine rupture in pregnancy. 2012. emdecine.medscape.com/article/overview. www.emedicine.medscape.com, accessed April.

25. Wandabwa J, Todd j P, Kiondo P, Aziga F: Risk factors for ruptured uterus in Mulago hospital Kampala Uganda. East Afr Med J, 85(2):64-71.

26. Kadowa I: Ruptured uterus in rural Uganda: prevalence, predisposing factors and out comes. Singapore Med J 2010, 51(1):35.

27. WHO, UNFPA, UNICEF 2009: Monitoring Emergency Obstetric care, a hand book.

28. Thaddeus S, Maine D: Too far to walk: maternal mortality in context. Soc Sci Med 1994, 38:1091-1110.

29. Dow M, Wax JR, Pinette MG, Blackstone J, Cartin A: Third- trimester uterine rupture without previous caesarean: a case series and review of literature. Am J Perinatal 2009, 26(10):739-744.

30. Dhaifalah $\mathrm{H}$, Santary J, Fingerova $\mathrm{H}$ : Uterine rupture during pregnancy and delivery among attending the AL-Tthawra hospital in Sana'a city, Yemen republic. Biomed pap med Fac Univ Palacky Olomouc Czech Repub 2006, 150(2):279-283.

31. Ekanem El, Etuk SJ, Ekott MI, Ekabua JE, Iklaki C: Socio-demographic profile and presentation of patients with ruptured gravid uterus in Calabar Nigeria. Niger J Med 2008, 17(1):78-82

32. Adamu RM, Obed SA: Ruptured uterus: a seven-year review of cases from Accra, Ghana. J Obstet Gynaecol Can 2003, 25(3):225-230.

33. Mokgokong ET: Treatment of uterine rupture. SAMJ 1976, 50(41):1621-1624

34. Ojenuwah SA, Olowosulu RO: Surgical management of ruptured gravid uterus in Bida, North central Nigeria. Trop Doct 2007, 37(4):219-221.

35. Ekpo EE: Uterine rupture as seen in the university of Calabar teaching Hospital, Nigeria: a five year review. J Obstet Gynaecol 2000, 20(2):154-156

36. Aboyeji AP, ljaiya MD, Yahaya UR: Ruptured uterus: a study of 100 consecutive cases in Ilorin, Nigeria. J Obstet Gynaecol Res 2001, 27(6):341-348.

37. Ahmed SM, Daffalla SE: Incidence of uterine rupture in a teaching hospital, Sudan. Saudi Med J 2001, 22(9):757-761.

38. Mbonye AK, Asiimwe JB, Kabarangira J, Nanda JG, Orinda V: Emergency obstetric care as the priority intervention to reduce maternal mortality in Uganda. Int J Gynaecol Obstet 2007, 96(3):220-225.

39. Orinda V, Kakande $H$, Kabarangira J, Nanda G, Mbonye AK: A sector wide approach to emergency obstetric care in Uganda. Int J Gynaecol Obstet 2005, 91(3):285-291.

40. Chuni N: Analysis of uterine rupture in a tertiary centre in eastern Nepal: lessons for obstetric care. J Obstet Gynaecol Res 2006, 32(6):574-579.

41. Rouzi AA, Hawaswi AA, Aboalazu M, Hassanain F, Sindi O: Uterine rupture incidence, risk factors and outcome. Saudi Med J 2003, 24(1):37-39.

42. O'Brien-Abel N: Uterine Rupture during VBAC, risk factors and fetal response. J Midwifery Women's Health 2003, 48(4):249-257.

43. Kabakyenga JK, Ostergren PO, Turyakira E, Mukasa PK, Pettersson KO Individual and health facility factors and the risk for obstructed labour and its adverse outcomes in south-western Uganda. BMC Pregnancy Childbirth 2011, 11:73.

44. Kyomuhendo GB: Low use of rural maternity services in Uganda: impact of women's status, traditional beliefs and limited resources. Reprod Health Matters 2003, 11:16-26.

45. Amooti-Kaguna B, Nuwaha F: Factors influencing choice of delivery sites in Rakai district of Uganda. Soc Sci Med 2000, 50:203-213.

46. Neilson JP, Lavender T, Quenby S, Wray S: Obstructed labour. Br Med Bull 2003, 67:191-204.

47. Lavender T, Hart A, Smyth RM: Effect of partograph use on outcomes of women in spontaneous labour at term. Cochrane Database Syst Rev 2008, 8(4):CD005461. Review.

48. Lavender $\mathrm{T}$, Lugina $\mathrm{H}$, Smith $\mathrm{H}$ : The partograph: a life saving tool for African midwives. Trop Doct 2007, 37(3):191-192.

49. Mathews M: The partograph for prevention of obstructed labour. Clin Obstet Gynaecol 2009, 52(2):256-269.
50. Kamatenesi-Mugisha M, Oryem-Origa H: Medicinal plants used to induce labour during childbirth in western Uganda. J Ethnopharmacol 2007, 109:1-9.

51. Gupta S: Medical legal issues in fertility regulation review Br. J Obstet Gynaecol 1998, 105:818-2.

52. Padhye SM: Rupture of the pregnant uterus: a 20 year review. Kathmandu Univ Med J 2005, 3:234-238.

doi:10.1186/1742-4755-10-29

Cite this article as: Mukasa et al:: Uterine rupture in a teaching hospital in Mbarara, western Uganda, unmatched case- control study.

Reproductive Health 2013 10:29.

\section{Submit your next manuscript to BioMed Central and take full advantage of:}

- Convenient online submission

- Thorough peer review

- No space constraints or color figure charges

- Immediate publication on acceptance

- Inclusion in PubMed, CAS, Scopus and Google Scholar

- Research which is freely available for redistribution

Submit your manuscript at www.biomedcentral.com/submit
C Biomed Central 